\title{
CIENCIAMATRIA
}

Revista Interdisciplinaria de Humanidades, Educación, Ciencia y Tecnología

Año VII. Vol. VII. N¹2. Enero - Junio. 2021

Hecho el depósito de ley: pp201602FA4721

ISSN-L: 2542-3029; ISSN: 2610-802X

Universidad Nacional Experimental Francisco de Miranda (UNEFM). Santa Ana de Coro. Venezuela

Rosa Angélica Zumba-Lucero; Juan Carlos Erazo-Álvarez; Gonzalo Iván Andrade-Mena

Cristián Andrés Erazo-Álvarez

DOI 10.35381/cm.v7i12.454

\section{Gestión del conocimiento y competitividad}

\section{Knowledge management and competitiveness}

\author{
Rosa Angélica Zumba-Lucero \\ razumbal18@est.ucacue.edu.ec \\ Universidad Católica de Cuenca, Cuenca \\ Ecuador \\ https://orcid.org/0000-0002-8605-1065 \\ Juan Carlos Erazo-Álvarez \\ jcerazo@ucacue.edu.ec \\ Universidad Católica de Cuenca, Cuenca \\ Ecuador \\ https://orcid.org./0000-0001-6480-2270 \\ Gonzalo Iván Andrade-Mena \\ gonzaloandrade@ucacue.edu.ec \\ Universidad Católica de Cuenca, Cuenca \\ Ecuador \\ https://orcid.org/0000-0003-2777-4260 \\ Cristián Andrés Erazo-Álvarez \\ cristianerazo@ucacue.edu.ec \\ Universidad Católica de Cuenca, Cuenca \\ Ecuador \\ https://orcid.org/0000-0001-8746-4788
}

Recibido: 01 de octubre de 2020

Aprobado: 15 de diciembre de 2020 


\title{
CIENCIAMATRIA \\ Revista Interdisciplinaria de Humanidades, Educación, Ciencia y Tecnología \\ Año VII. Vol. VII. Nº12. Enero - Junio. 2021 \\ Hecho el depósito de ley: pp201602FA4721 \\ ISSN-L: 2542-3029; ISSN: 2610-802X \\ Universidad Nacional Experimental Francisco de Miranda (UNEFM). Santa Ana de Coro. Venezuela
}

Rosa Angélica Zumba-Lucero; Juan Carlos Erazo-Álvarez; Gonzalo Iván Andrade-Mena

Cristián Andrés Erazo-Álvarez

\section{RESUMEN}

El objetivo principal es analizar la gestión del conocimiento y competitividad en la Hacienda La Candelaria, con el objeto de que esa empresa conozca el alcance y debilidad para cumplir con los requerimientos de la norma orgánica de producción europea y eventualmente alcance su certificación. Se desarrolló desde el enfoque cuantitativo y una metodología de tipo descriptiva con diseño transversal no experimental, en una muestra poblacional conformada por 47 trabajadores de a Hacienda La Candelaria, ubicada en la Provincia de Chimborazo - Ecuador. La hacienda tiene fallas en el seguimiento y ayuda a las dificultades que tienen sus trabajadores en la ejecución de su trabajo, lo cual es contraproducente porque tales insuficiencias pueden estarse solventando de modos contraproducentes a la calidad que busca la empresa.

Descriptores: Gestión del conocimiento; transferencia de conocimiento; sistema de información de gestión. (Palabras tomadas del Tesauro UNESCO).

\begin{abstract}
The main objective is to analyze the management of knowledge and competitiveness at Hacienda La Candelaria, in order for that company to know the scope and weakness to comply with the requirements of the organic European production standard and eventually achieve its certification. It was developed from a quantitative approach and a descriptive methodology with a non-experimental cross-sectional design, in a population sample made up of 47 workers from Hacienda La Candelaria, located in the Province of Chimborazo - Ecuador. The hacienda has failures in monitoring and helps with the difficulties that its workers have in the execution of their work, which is counterproductive because such deficiencies may be solving in ways that are counterproductive to the quality that the company seeks.
\end{abstract}

Descriptors: Knowledge management; know-how transfer; management information systems. (Words taken from the UNESCO Thesaurus). 


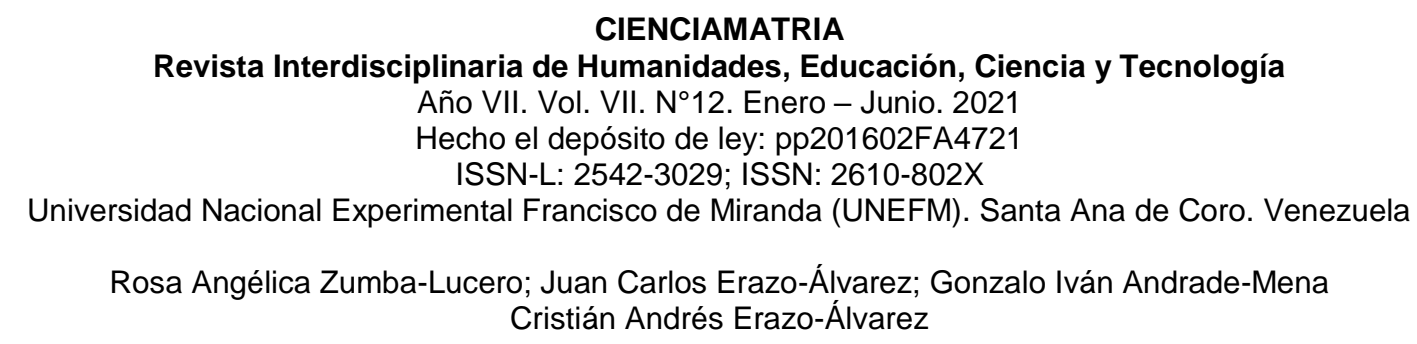

\section{INTRODUCCIÓN}

La Gestión del conocimiento (Knowledge Management, KM) se ha constituido en una herramienta para que las organizaciones mejoren su productividad y competitividad mediante la obtención de conocimientos y competencias específicas (Benavides \& Quintana, 2003). Esto implica un proceso de gestión del conocimiento para crear, acopiar, compartir, difundir y usar conocimiento en la organización (Girard \& Girard, 2015). En la industria bananera se hace hoy en día imprescindible la incorporación de la gestión del conocimiento en virtud de la complejidad que ha adquirido el mercado, que afecta su competitividad internacional. En el negocio de la banana se están produciendo una serie de cambios que desafían la industria bananera ecuatoriana.

Entre otros aspectos, se pueden mencionar los siguientes: países que han mejorado la producción de la fruta para su exportación; nuevos países exportadores; mercados más exigentes con normas técnicas en toda la línea del proceso de producción y comercialización; aumento de empresas comercializadoras del producto; y la amenaza de plagas, como el hongo "Fusarium Wilt", especialmente la variedad denominada Tropical (Vásquez-Ramírez \& Castaño-Zapata, 2017), (FAO , 2019).

Las investigaciones han concluido que los costos de producción en el Ecuador, son aceptables y el país debe volcarse a la exportación (UNCTAD, 2014); (Rosero, 2001). Tanto la mano de obra, la inversión de capital, como la zona de cultivo mantienen costos que permiten ser competitivos generando una productividad promedio de $33.25 \mathrm{Tm} / \mathrm{ha}$. en el país. La producción total de bananos de Ecuador en 2018 fue de 345 millones de cajas, por un valor superior a los USD 3.100 millones, lo que representó un crecimiento de 5.33\% con relación al 2017 (FAO, 2019).

La gestión del conocimiento en la industria bananera tiene que insertarse en toda la cadena de valor para que su efectividad sea posible, esto es: en la producción, la distribución, la comercialización y el transporte, ya que todas ellas añaden al producto final la calidad que las normas orgánicas requieren. 


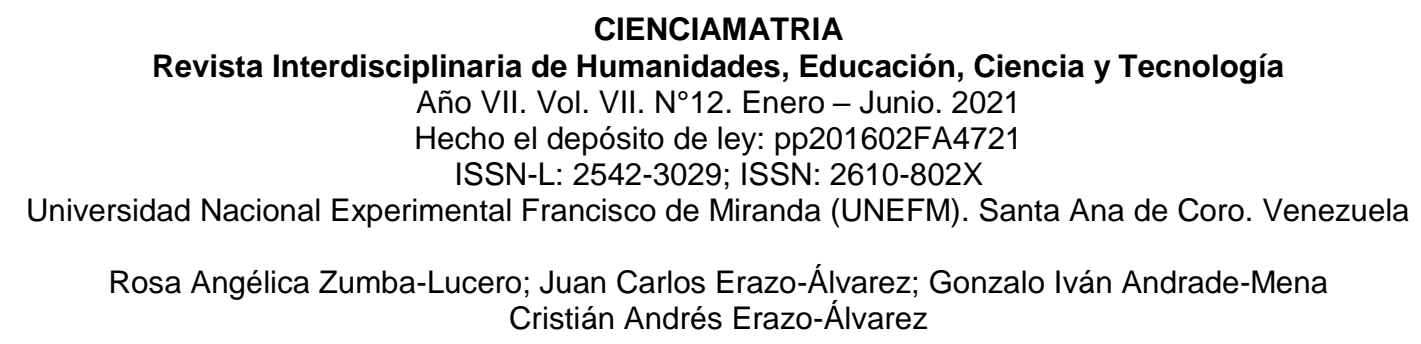

Atendiendo a esos requerimientos, el estudio se centra en La Hacienda la Candelaria, la cual es una explotación familiar de unas 40 hectáreas, propiedad del Sr. Adam Patricio, que produce 2.400 cajas de bananos (50\% bajo contrato). Esta empresa cuenta con 47 trabajadores e instalaciones para cosechar, conservar, acopiar, procesar el fruto y el descartable. Es una finca que ha logrado satisfacer las exigencias que dispone la certificación (GLOBALG.A.P., 2020), lo cual la coloca en situación de poder plantearse otros desafíos que incrementen su competitividad en el contexto de las complejas condiciones del mercado bananero actual.

En ese sentido, el trabajo se enfocó en investigar ¿Cómo la aplicación de la gestión del conocimiento en la Hacienda la Candelaria incide en su desempeño organizacional con la aplicación de las normas de producción orgánica de banano más exigentes? Los cambios en el mercado bananero promovidos principalmente por el surgimiento de nuevas empresas competidoras y las elevadas exigencias que los países consumidores imponen a la importación del banano, desafían a la Hacienda la Candelaria a afrontar el logro de certificaciones de producción orgánica como es la de la Unión Europea, basada en el (Organización de las Naciones Unidas para la Alimentación y la Agricultura, 2020) para ser más competitiva y sostenible en el largo plazo.

En atención a lo expuesto, el objetivo principal es analizar la gestión del conocimiento y competitividad en la Hacienda La Candelaria, con el objeto de que esa empresa conozca el alcance y debilidad para cumplir con los requerimientos de la norma orgánica de producción europea y eventualmente alcance su certificación.

\section{Referencial teórico}

En este punto se presentan los enfoques teóricos que sustentan el trabajo de investigación que se desarrolló. Está compuesto por una revisión general del papel de la gestión del conocimiento en la empresa moderna, la referencia a algunos antecedentes de investigación que fueron considerados de interés y la exposición de la importancia de 


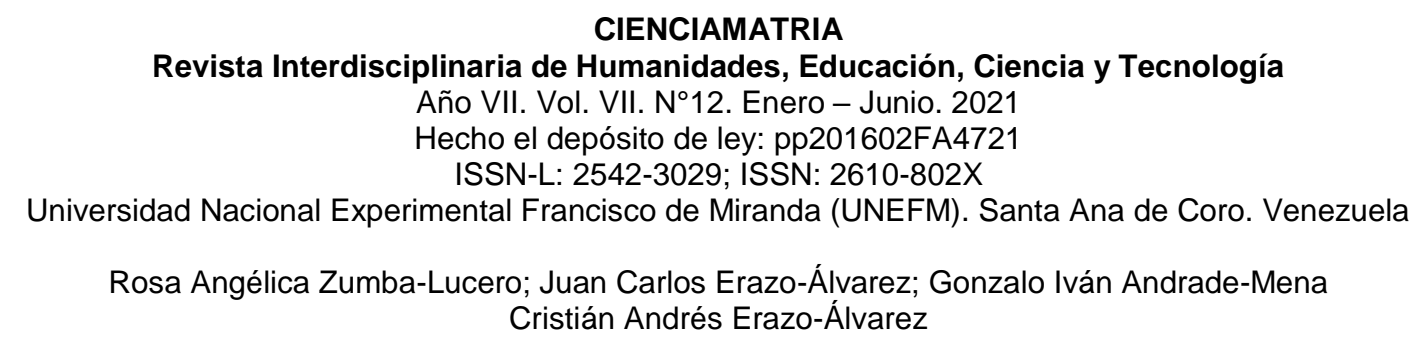

la gestión del conocimiento en la empresa bananera. Este marco referencial cumple el papel de apoyar la distinción de los indicadores para la recolección de datos en la Hacienda La Candelaria y analizarlos de modo cuantitativo.

\section{La gestión del conocimiento y la empresa}

Para producir bienes y/o servicios las personas se organizan bajo la modalidad de empresas. La principal característica de una empresa es que se forma mediante un contrato o escritura constitutiva, en donde se define sus fines, dueños y actividad productiva a realizar. Lo anterior lleva a la definición de sociedad anónima (corporación). Según (Stanclife, 1917), la corporación sería una institución con el objetivo pecuniario de ganar o evadir pérdidas en dinero para el beneficio de sus miembros.

En la época moderna las empresas enfrentan situaciones sociales y económicas complejas que las han llevado a adoptar enfoques organizacionales y de mercado que les permitan acoplarse a condiciones cambiantes. En esa línea, el enfoque empresarial estratégico ha constituido un aporte importante para la gestión de las empresas, orientado a que estas dirijan y desarrollen su actividad dentro de propósitos definidos, congruencia de valores y líneas de actuación acordes al entorno circundante y a la propia realidad interna (Avila Ramírez, et al., 2018), (Mintzberg, 1987), para obtener mejores posicionamientos en los mercados, competir con calidad y sostenibilidad en el tiempo.

Quienes llevan las riendas de una organización o empresa, se encuentran con los siguientes desafíos: 1) Evaluar sistemáticamente la estructura y la situación económicofinanciera de la empresa para determinar su poder de generar beneficios en el corto y largo plazo; 2) Determinar la capacidad de la organización para hacer frente a los desafíos sistemáticos o del entorno de negocios; 3) Evaluar y aplicar estrategias de financiamiento acordes con las posibilidades de la empresa; y 4) Establecer mecanismos de vigilancia y control que complemente lo diseñado en el presupuesto de la empresa. 


\section{CIENCIAMATRIA \\ Revista Interdisciplinaria de Humanidades, Educación, Ciencia y Tecnología \\ Año VII. Vol. VII. N¹2. Enero - Junio. 2021 \\ Hecho el depósito de ley: pp201602FA4721 \\ ISSN-L: 2542-3029; ISSN: 2610-802X \\ Universidad Nacional Experimental Francisco de Miranda (UNEFM). Santa Ana de Coro. Venezuela}

Rosa Angélica Zumba-Lucero; Juan Carlos Erazo-Álvarez; Gonzalo Iván Andrade-Mena

Cristián Andrés Erazo-Álvarez

En la perspectiva estratégica los imperativos antes mencionados requieres que quienes dirigen la organización y sus colaboradores respondan permanentemente las siguientes interrogantes: 1) ¿Cuál es el principal negocio en el que se encuentra la empresa?; 2) ¿Cuál es la misión de la organización?; 3) ¿Es ésta una empresa líder en su industria?; 4) ¿Habrá demanda para los productos/servicios en los próximos años?; 5) ¿Quiénes son los competidores más importantes?; 6) ¿Cuáles son sus fortalezas y debilidades organizacionales?; 7) ¿Cuáles son sus amenazas y oportunidades?; 8) ¿Cuáles son los factores claves del éxito de la empresa?; 9) ¿Cuáles son las metas y los objetivos organizacionales?; 10) ¿Reconoce la gerencia de la empresa su responsabilidad?

Lo anterior implica considerar a la empresa desde el punto de vista organizacional, donde la empresa despliega el ciclo productivo (Borgucci, 2013). Ejemplificando con el ciclo productivo del banano, este contiene aspectos particulares dada su naturaleza agrícola (InfoAgro, 2020), que comienza con las faenas relacionadas a la preparación del lote de terreno dedicado a la siembra (condiciones agrológicas como clima, humedad, nutrientes, acidez de los suelos, entre otras muchas cosas); selección de las variedades de banano, Cavendish, Orito, Rojo, entre otras variedades; las condiciones de recolección, almacenaje, empaque, comercialización venta y distribución del producto, todo lo cual implica la organización técnica, administrativa y gerencial que haga posible el sostenimiento del ciclo productivo indicado en el tiempo.

De allí que, el ciclo organizacional es el conjunto, donde el ciclo productivo o comercial es un componente. Todas las actividades que desempeñan la gerencia y los colaboradores implican un flujo de tareas coordinadas dentro de procesos productivos y administrativos. Detrás de esas tareas y procesos se encuentran los flujos de información y sus procesos asociados. Pues bien, para desarrollar una tarea se necesita conocer su naturaleza, su finalidad y sobre todo su aplicación para obtener los resultados esperados. Es decir, cada tarea y actividad implica el dominio de sus flujos de producción (actividades 


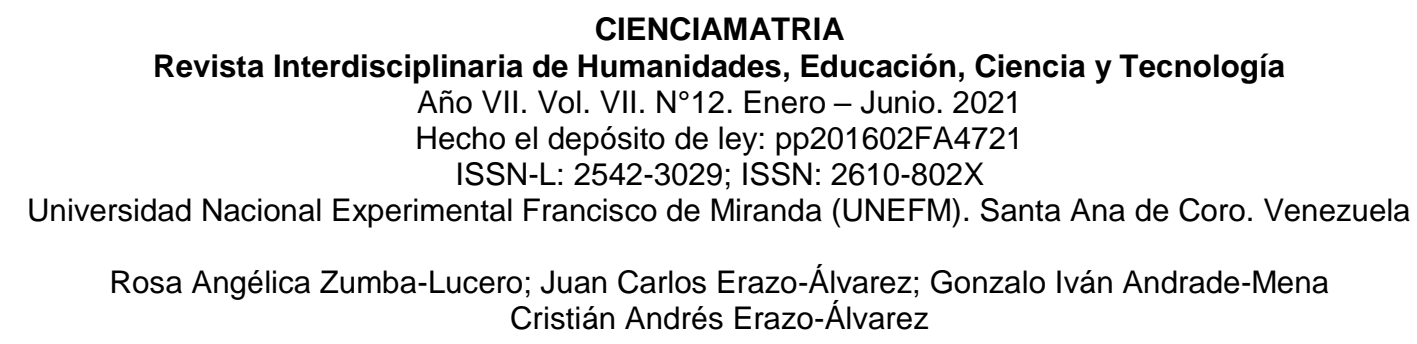

productivas y comerciales) e información (cadena de toma de decisiones que se deben adoptar, basadas en normas y políticas de la organización) (Borgucci, 2013).

La gerencia en ese sentido, es la instancia encargada de coordinar la toma de decisiones y acciones (planificación, proyectos y presupuesto) para llevar a la empresa al éxito económico-financiero y alcanzar los objetivos productivos y organizacionales. En los últimos 30 años numerosas empresas pasan a desarrollar estrategias de producción que se basan en el aprendizaje a partir de la experiencia, dado los avances que se producen en la disciplina de la gestión el conocimiento (Pérez-Montoro, 2016). Con la introducción de esos criterios los equipos gerenciales y operativos han podido acceder a flujos extraordinarios de información dentro y fuera de la empresa para mantener y desarrollar ventajas comparativas tradicionales y potenciales, alimentándose del conocimiento que pueden captar, producir y distribuir para favorecer los propósitos empresariales.

La Gestión del conocimiento (Knowledge Management, KM) mejora todos aquellos factores que permiten un desempeño superior de la organización tales como la creatividad organizacional, la efectividad operacional y la calidad de sus productos y servicios (Wiig, 1993). En ese sentido, se considera que el conocimiento es una mezcla fluida de estructuras de experiencias, valores, información contextual y una visión aguda que provee de una estructura para evaluar e incorporar nuevas experiencias e información (Davenport \& Prusak, 1998).

En este sentido, la gestión del conocimiento es el logro del progreso económico mediante el intercambio de éste entre las personas (Zamora, 2003). Implica también, la distribución del conocimiento tácito y explícito a cada miembro de la organización de manera eficaz, con la finalidad de lograr mayores niveles de productividad laboral (Del Moral, et al., 2007). Finalmente, la Gestión del conocimiento es una herramienta para lograr los objetivos organizacionales mediante procesos de creación, compartir, usar y gerenciar el conocimiento acumulado en la organización (Girard \& Girard, 2015). 


\section{CIENCIAMATRIA \\ Revista Interdisciplinaria de Humanidades, Educación, Ciencia y Tecnología \\ Año VII. Vol. VII. N¹2. Enero - Junio. 2021 \\ Hecho el depósito de ley: pp201602FA4721 \\ ISSN-L: 2542-3029; ISSN: 2610-802X \\ Universidad Nacional Experimental Francisco de Miranda (UNEFM). Santa Ana de Coro. Venezuela}

Rosa Angélica Zumba-Lucero; Juan Carlos Erazo-Álvarez; Gonzalo Iván Andrade-Mena Cristián Andrés Erazo-Álvarez

El conocimiento organizacional en la gerencia es analizado en diferentes niveles de abstracción. Unos estudios distinguen entre información (conocer qué) y habilidades combinadas (conocer cómo) (Kogut \& Zander, 1997). Una distinción parecida, separa conocimiento técnico e innovación del conocimiento tácito con las habilidades personales y la rutina organizacional (Tordoir, 1995). Otros autores distinguen entre conocimiento tácito del conocimiento articulado (Nonaka \& Takeuchi, 1995). Después, otro grupo de autores distinguen lo que se conoce como "conocimiento profesional" del conocimiento de una firma en específico, estableciendo una distinción entre el conocimiento científicofilosófico del comercial (Tordoir, 1995); (Demarest, 1997).

Entre las principales áreas de aplicación de la gestión del conocimiento en las organizaciones (sociedades mercantiles) se encuentran: el uso racional del conocimiento, la definición de procesos, el estudio de los procesos de evaluación o la aplicación de programas de gestión del conocimiento. La primera área tiene como fundamentos teóricos: el manejo de la información económica y la gerencia estratégica. La segunda área expone los siguientes fundamentos teóricos: la cultura organizacional, la estructura organizacional, el comportamiento organizacional y la inteligencia artificial. En la tercera área se han desarrollado los siguientes fundamentos: la calidad de la gerencia y la medida del desempeño organizacional.

Los principales aportes en cada aspecto fundacional de la Gestión del conocimiento son: 1) dentro de la Economía de información: la economía del conocimiento, las redes de conocimiento, los activos de conocimiento, el conocimiento distribuido y la continuidad de la gestión (Tordoir, 1995); (Inkpen \& Tsang, 2005); (Teece, 2000); (Foray, 2004); (Beazley, et al., 2002); 2) dentro de la Gerencia estratégica se encuentran estudios sobre alianzas del conocimiento, conocimiento estratégico, conocimiento del mercado y capacidad de conocimiento (Conner \& Prahalad, 1996); (Eisenberg, 1997); (Kafentzis, Mentzas, et al., 2004); 3) en cultura organizacional, los trabajos se dirigen hacia la cultura del conocimiento (Graham \& Pizzo, 1996); (De Long \& Fahey, 2000); 4) dentro de los 


\section{CIENCIAMATRIA \\ Revista Interdisciplinaria de Humanidades, Educación, Ciencia y Tecnología \\ Año VII. Vol. VII. Nº12. Enero - Junio. 2021 \\ Hecho el depósito de ley: pp201602FA4721 \\ ISSN-L: 2542-3029; ISSN: 2610-802X \\ Universidad Nacional Experimental Francisco de Miranda (UNEFM). Santa Ana de Coro. Venezuela \\ Rosa Angélica Zumba-Lucero; Juan Carlos Erazo-Álvarez; Gonzalo Iván Andrade-Mena \\ Cristián Andrés Erazo-Álvarez}

estudios de la estructura organizacional, se encuentran los estudios de conocimiento organizacional (Starbuck, 1997); (Dyer \& Nobeoka, 2000); 5) en comportamiento organizacional se encuentran estudios sobre creación del conocimiento o la transferencia del conocimiento (Wiig, 1993); (Nonaka \& Takeuchi, 1995); (Nonaka \& Toyama, 2003); 6) en inteligencia artificial se estudia preferentemente la infraestructura del conocimiento, la arquitectura del conocimiento o el descubrimiento del conocimiento (Fayyad, PiatetskyShapiro, \& Smyth, 1996); (Davenport, De Long, \& Beers, 1998); (Nonaka \& Toyama, 2003); 7) en calidad de la gerencia, los estudios están dirigidos a conocer las estructuras cualitativas de las organizaciones y la equidad del conocimiento (Glazer, 1998); (Jordan \& Jones, 1997); (King \& Zeithaml, 2003); y 8) en medida del desempeño organizacional, se estudian, por ejemplo, el desarrollo de mejores índices de desempeño (Ahn \& Chang, 2004); (Chang, et al., 2005).

Se entiende que La Hacienda La Candelaria, una organización con un determinado número de empleados y trabajadores, que se dedica a la producción y comercialización del banano y el plátano, constituye un buen ejemplo de aplicación de la Gestión del conocimiento en un entorno productivo primario.

\section{Antecedentes de interés para la investigación}

Un análisis a resaltar es el estudio base para la Revisión de Política Comercial de Exportaciones Verdes del Ecuador (RPCEV) realizado por la UNCTAD (2014), donde se concluye que el banano orgánico alcanzó el 3,3\% de las exportaciones totales de esa ruta, siendo esa cifra más baja que la del café orgánico $(5,2, \%)$ y del cacao $(4 \%)$. También se afirma en el informe que los diferenciales de precio, tanto del café como del banano orgánicos, señalan buen espacio para el crecimiento.

Se señala, además, que son objetivos del Estado ecuatoriano apoyar el mejoramiento de la productividad, la innovación y agregar valor a la economía de productos verdes, ente los cuales está el banano. Esos elementos expuestos indican las posibilidades que se le 


\section{CIENCIAMATRIA \\ Revista Interdisciplinaria de Humanidades, Educación, Ciencia y Tecnología \\ Año VII. Vol. VII. Nº12. Enero - Junio. 2021 \\ Hecho el depósito de ley: pp201602FA4721 \\ ISSN-L: 2542-3029; ISSN: 2610-802X \\ Universidad Nacional Experimental Francisco de Miranda (UNEFM). Santa Ana de Coro. Venezuela \\ Rosa Angélica Zumba-Lucero; Juan Carlos Erazo-Álvarez; Gonzalo Iván Andrade-Mena Cristián Andrés Erazo-Álvarez}

abren a la producción orgánica de banano en el país y también las de establecer alianzas con organismos gubernamentales, universidades y centros de investigación que apoyen políticas de gestión del conocimiento en las empresas bananeras.

Estudios realizados identifican aspectos para el manejo del control de la calidad en la finca bananera Nelly Beatriz que el rigor de las normas internacionales dispone para acceder a la importación del banano, como son el manipuleo del producto en la cosecha, clasificación, limpieza, empaquetado y traslado, todo lo cual necesita de correcciones para reducir las pérdidas que se producen en el curso del proceso.

Cumplir tales requerimientos demanda de conocimientos y técnicas para que ese proceso sea sostenible y de calidad. Asimismo, estos estudios aluden a obstáculos de fondo que no solo afectan a la finca particular que analizan, sino a la industria bananera en su conjunto como son: problemas de comercialización, técnicos, fenómenos naturales, efectos de los químicos en la coloración y madurez del producto, cambios ambientales, disminución de la biodiversidad, erosión y desequilibrio de los componentes del suelo (Pardo \& Novillo, 2016).

Los trabajos mencionados ponen de manifiesto que la superación de los obstáculos que rodean la producción del banano, y orgánica en particular, no puede llevarse a cabo sin un plan de gestión del conocimiento en la empresa que permita conocer y reconocer a tiempo las dificultades y cómo resolverlas con la participación activa de gerentes, coordinadores y de los trabajadores que son quienes manipulan y realizan el proceso preparatorio para la exportación. Pero se pone de relieve que la magnitud de los obstáculos exige algo más, y es la concertación con organismos gubernamentales y académicos que permitan el entendimiento y resolución de dificultades para el mantenimiento de la calidad del banano y la protección ambiental para la sostenibilidad. 


\section{CIENCIAMATRIA \\ Revista Interdisciplinaria de Humanidades, Educación, Ciencia y Tecnología \\ Año VII. Vol. VII. Nº12. Enero - Junio. 2021 \\ Hecho el depósito de ley: pp201602FA4721 \\ ISSN-L: 2542-3029; ISSN: 2610-802X \\ Universidad Nacional Experimental Francisco de Miranda (UNEFM). Santa Ana de Coro. Venezuela \\ Rosa Angélica Zumba-Lucero; Juan Carlos Erazo-Álvarez; Gonzalo Iván Andrade-Mena \\ Cristián Andrés Erazo-Álvarez}

\section{Gestión del conocimiento en la empresa bananera}

La razón de enfocar el estudio hacia la gestión del conocimiento en la Hacienda La Candelaria tiene razones estratégicas referidas a su competitividad en el mercado, que pueden expresarse de este modo: 1) que la empresa se debe preparar a enfrentar una situación más restringida posiblemente por la baja en la demanda mundial de plátano y banano o de las variaciones desfavorables en sus precios; 2) la necesidad de adoptar nuevas normas de calidad internacional para preservar las ventajas competitivas adquiridas; 3) la posibilidad de explorar nuevos negocios dentro del mundo del banano y el plátano, lo que podría llevar a la empresa a desarrollar nuevas unidades estratégicas de negocios (UEN).

Esto último es importante debido a que el banano y el plátano pueden estar siendo objeto de al menos cuatro procesos: 1) nuevos usos del plátano y el banano más allá del consumo final (nuevos alimentos, medicinas, productos de belleza, entre otros); 2) lo anterior lleva a una mayor industrialización del recurso; 3) esos nuevos usos e industrialización exigirán recursos para la investigación y desarrollo; 4) todo lo anterior generará nuevos canales de comercialización, ya sean con nuevos intermediarios o con los tradicionales. En resumen, se estará presentando un cambio, por vía de la ampliación, del sector bananero y en conjunto del "negocio bananero", en donde el mayor potencial se concentrará en su industrialización a gran escala.

De los procesos antes mencionados, la Hacienda La Candelaria podría formar parte siempre y cuando represente posibilidades de rédito. Es responsabilidad de la gerencia a nivel estratégico visualizar las ventajas competitivas, las sinergias y las competencias distintivas de su producto principal y con la ayuda de la gestión del conocimiento trasladar esa perspectiva a la gerencia funcional y operativa.

Ahora bien, en el negocio de la banana lenta pero progresivamente se están produciendo una serie de cambios que podrían representar un serio desafío para la industria bananera ecuatoriana y en concreto para la Hacienda La Candelaria desde el punto de vista 


\section{CIENCIAMATRIA \\ Revista Interdisciplinaria de Humanidades, Educación, Ciencia y Tecnología \\ Año VII. Vol. VII. N¹2. Enero - Junio. 2021 \\ Hecho el depósito de ley: pp201602FA4721 \\ ISSN-L: 2542-3029; ISSN: 2610-802X \\ Universidad Nacional Experimental Francisco de Miranda (UNEFM). Santa Ana de Coro. Venezuela}

Rosa Angélica Zumba-Lucero; Juan Carlos Erazo-Álvarez; Gonzalo Iván Andrade-Mena

Cristián Andrés Erazo-Álvarez

estratégico. En primer lugar, se tiene la entrada en competencia con más ímpetu de Costa Rica, Colombia, Guatemala y la República Dominicana y Perú. Colombia es uno de los grandes productores mundiales y tiene larga experiencia en el sector, por lo cual podría ser un fuerte competidor en el mediano plazo. Algo parecido sucede con Costa Rica y Guatemala, que son productores tradicionales y con experiencia exportadora.

Lo llamativo es la entrada de la República Dominicana, que se considera como un país con poca producción y quizá con un horizonte de producción pequeño; pero tiene la ventaja de contar con tierras de cultivo aptas para el banano y estar cerca de dos grandes mercados como lo son los Estados Unidos de América y Europa, ambos clientes tradicionales de Ecuador (FreshPlaza, 2020); (Martinez, et al., 2007).

En segundo lugar, se encuentran grandes productores que solo abastecían principalmente el mercado nacional y que se están convirtiendo en exportadores tales como India y Brasil. La importancia de la India estriba que aparte de poseer un gran mercado interno está incursionando con sus exportaciones, lo cual lo ha mantenido como el primer productor mundial con posibilidades de seguir creciendo, ya que su producción atendería al mercado de Asia, Rusia y Europa Occidental, por estar relativamente más cerca que la República Popular China, otro de los grandes productores mundiales, y sobre todo de Ecuador. Otro país que es una potencia mundial en la producción de banano es Brasil, sin embargo, es quizá el país con mayor potencial productivo, por la amplísima disponibilidad de tierras, infraestructura portuaria y aeroportuaria, mano de obra barata y estar relativamente más cerca geográficamente de Europa y Estados Unidos que Ecuador (Martinez, et al., 2007).

Además de la entrada de nuevos países en la competencia por el mercado del banano, los grandes consumidores de banano como lo es la Unión Europea podrían establecer regulaciones más estrictas en lo relacionado a la producción y las prácticas de comercio justos, independientemente que Ecuador haya firmado convenios de comercio bilateral como el Acuerdo Comercial Multipartes entre Ecuador y la Unión Europea y el 


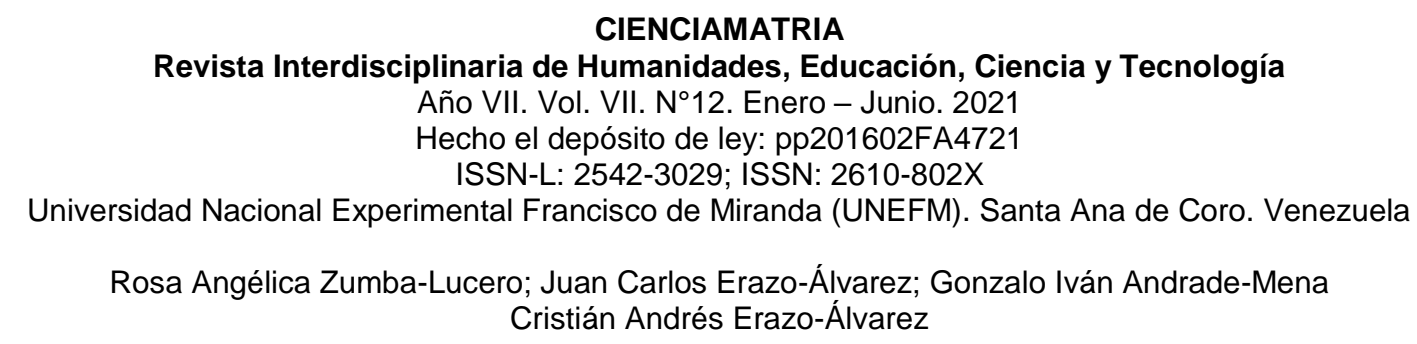

denominado Acuerdo de Ginebra del 15 de diciembre de 2009, con el cual se saldó la disputa del banano. Además, en Europa se están orientando a la "Denominación de Origen Controlada" en distintos productos para establecer niveles de calidad (FAO, 2019).

Ahora bien, Europa, América del Norte y Japón, que representan el $99 \%$ de las importaciones de banano orgánico y gran porcentaje de las importaciones del banano mundial, establecieron una serie de certificaciones, como son la "Norma orgánica europea", la "Norma Agrícola Japonesa" y la de 2001 y la Ley de producción de Alimentos Orgánicos de 1990 de Estados Unidos (FAO, 2019). Para exportar, Ecuador cuenta con sus casas comercializadoras, sin embargo, la distribución internacional está dominado por un conjunto de empresas con gran músculo financiero, una cartera enorme de clientes, logística de la distribución física, transporte, instalaciones para madurar la fruta y sobre todo poder de negociación.

No obstante, existe la competencia entre comercializadoras de banano a nivel internacional donde las principales empresas son Chiquita, Fresh Del Monte, DoleFood Company y Fyffes. En la actualidad se está popularizando la realización de alianzas entre empresas nacionales y extranjeras y entre empresas extranjeras. Esas alianzas incluyen a proveedores nacionales, mayoristas y supermercados. Una de esas alianzas es la que se dio entre Chiquita, una empresa estadounidense, y Fyffes que es de origen irlandés. Esta alianza denominada Chiquita Fyffes dominará tanto el mercado estadounidense como el europeo occidental.

La tendencia antes expuesta para las grandes firmas se ratifica en Ecuador. Así, como hay empresas de capital ecuatoriano también hay empresas de capital ecuatoriano y foráneo como es el caso de Dole y Reybanpac. Sin embargo, la cuestión para los productores es contar con el poder de negociación, la organización y la flexibilidad para lograr buenos acuerdos con las comercializadoras (Reyes, et al., 2020). Para eso se 


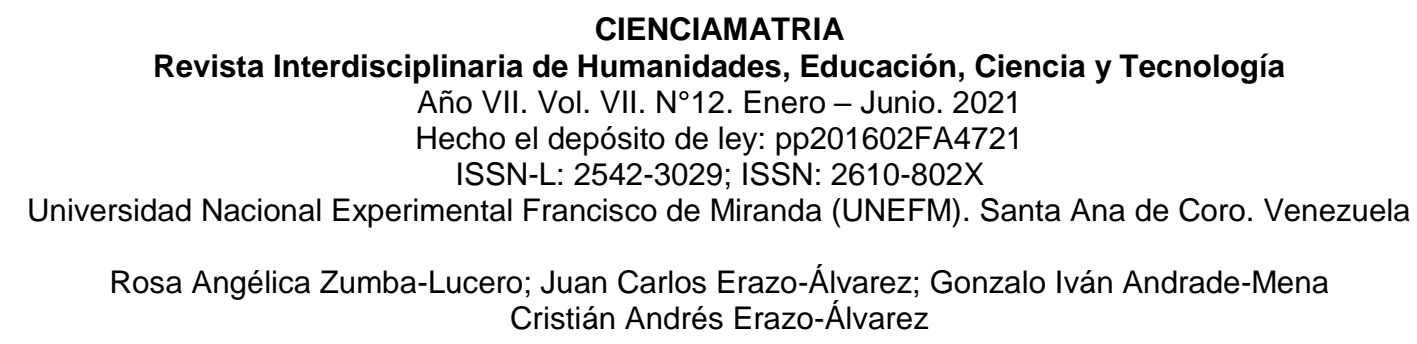

requiere que las empresas desarrollen competencias en materia productiva y de mercadeo para mejorar sus ventajas competitivas.

Uno de los desafíos que deberán atender los productores de banano y plátano del Ecuador y en concreto la Hacienda La Candelaria es la enfermedad provocada por el Fusarium Wilt, que está afectando severamente las plantaciones bananeras, especialmente la variedad denominada Tropical race 4 (TR4) (FAO, 2019). El problema se presenta porque no se ha logrado encontrar un fungicida efectivo o algún método efectivo de control. Por el momento, los países más afectados han sido aquellos ubicados en al Sur y Suroeste de Asia, principalmente por la longevidad del hongo en el suelo dedicado a la producción, lo que ha producido el abandono de la producción de banano y el cambio de rubro. Lo negativo del asunto para Ecuador es que el TR4 no está tan lejos. En julio de 2019, el fungus fue detectado por primera ocasión en América Latina en la Región de la Guajira Colombiana en el Departamento de la Guajira.

Si bien, la Hacienda la Candelaria goza de la certificación Global GAP, deberá ver la posibilidad de obtener más certificaciones de calidad, con la finalidad de crear un disuasivo frente a la competencia, manteniendo una estructura de costos que haga viable el negocio. Es decir, las empresas productoras de banano deberán asumir la producción orgánica de manera definitiva y eso incluye a la Hacienda La Candelaria. La tendencia Entre otras razones, debido a que el mercado, como se dijo más arriba tiende hacia la cultura del vino en lo relacionado a la normativa de calidad que lo caracteriza y con ello la posibilidad de lograr mayores ingresos y mayor valor económico de la explotación. Las nuevas normativas de calidad, de alguna manera, seguirán lo establecido al respecto por la (FAO, 2020) y cuyas ventajas son:

1. Mejora de la condición del suelo de la finca productora;

2. Protección de los recursos naturales de la finca;

3. Reducción de la contaminación de las fuentes de agua y de la huella de carbono (aunque el transporte sigue siendo el tema más central); 
Revista Interdisciplinaria de Humanidades, Educación, Ciencia y Tecnología

Año VII. Vol. VII. N¹2. Enero - Junio. 2021

Hecho el depósito de ley: pp201602FA4721

ISSN-L: 2542-3029; ISSN: 2610-802X

Universidad Nacional Experimental Francisco de Miranda (UNEFM). Santa Ana de Coro. Venezuela

Rosa Angélica Zumba-Lucero; Juan Carlos Erazo-Álvarez; Gonzalo Iván Andrade-Mena Cristián Andrés Erazo-Álvarez

4. Protección de la biodiversidad (agrobiodiversidad y silvestre) y bienestar animal;

5. Protección de la salud humana, por el empleo de menos fungicidas y plaguicidas así como otros productos químicos agresivos;

6. Trazabilidad mejorada;

7. Mayor acceso a los mercados locales, regionales e internacionales;

8. Apoyo a las economías locales y potencial para el desarrollo rural;

9. Acceso a financiamiento adicional y programas de asistencia técnica;

10. Facilitación del comercio, permitiendo a los agricultores vender, etiquetar y presentar los productos como orgánicos;

11. Mejor reconocimiento del consumidor;

12. La certificación de grupo abre potencial para la cooperación y el desarrollo rural;

13. Aunque la certificación orgánica no garantiza un precio mínimo establecido por el programa de certificación, el mercado ha determinado históricamente una mayor rentabilidad para los bananos orgánicos sobre los que no están certificados como orgánicos; y

14. El precio más alto de los bananos orgánicos también ha demostrado ser más estable que el precio de los bananos convencionales.

En ese sentido, la Hacienda La Candelaria debería aplicar las normas de certificación orgánica del banano en la finca, con los recursos disponibles y las limitaciones que afrontan. Una de las estrategias que podría emplear la empresa para lograr la certificación orgánica y darle continuidad al proceso es por medio de un esquema de gestión de conocimiento. Ahora bien, el proceso de certificación que es una norma sugerida por la (FAO, 2020), contiene los siguientes elementos:

1. Adopción de prácticas orgánicas en el esquema productivo de la finca. En ese sentido, se requiere "la prueba de calidad del suelo" y un "plan de rotación para rehabilitar los recursos durante un periodo de tiempo que va entre 2 y 3 años. En 
Revista Interdisciplinaria de Humanidades, Educación, Ciencia y Tecnología

Año VII. Vol. VII. N¹2. Enero - Junio. 2021

Hecho el depósito de ley: pp201602FA4721

ISSN-L: 2542-3029; ISSN: 2610-802X

Universidad Nacional Experimental Francisco de Miranda (UNEFM). Santa Ana de Coro. Venezuela

Rosa Angélica Zumba-Lucero; Juan Carlos Erazo-Álvarez; Gonzalo Iván Andrade-Mena

Cristián Andrés Erazo-Álvarez

ese periodo, las sustancias prohibidas no deben ser empleadas en la producción durante los últimos tres años de manera consecutiva.

2. Es la selección de la autoridad de certificación para iniciar el proceso de certificación orgánica pagando la tarifa correspondiente.

3. Revisión de los documentos por parte de la autoridad de certificación para constatar el cumplimiento de las normas de certificación.

4. El desarrollo el proceso de auditoría que implicará una inspección en el domicilio de la empresa (finca).

5. Realización del informe de inspección en donde se reseñarán los aspectos positivos (cumplimiento de los requisitos de la norma) y de las observaciones junto a las soluciones en caso de que no se cumplan los requisitos establecidos por la norma.

6. Se procede a la verificación que el solicitante cumpla con la norma, el certificado puede ser emitido y el producto puede ser etiquetado como orgánico.

7. Una vez cumplidos con los seis pasos anteriores, comienza el proceso de renovación, que se realizará cada año por parte de la empresa auditora.

Los nuevos desafíos que deberá afrontar la Hacienda la Candelaria son los siguientes:

1. Dificultad para cumplir con los requisitos de calidad de la norma.

2. La Gama limitada de insumos agrícolas para controlar.

3. Plagas y enfermedades (especialmente ya que la Sigatoka Negra se encuentra en la mayoría de los países productores de banano orgánico).

4. Los costos de certificación asociados con el monitoreo interno del proceso de producción.

5. Los costos y la dificultad para convertir plantaciones industriales.

6. El desafío de la adaptación regional y armonización de normas para construir equivalencias y cooperación. 


\section{CIENCIAMATRIA \\ Revista Interdisciplinaria de Humanidades, Educación, Ciencia y Tecnología \\ Año VII. Vol. VII. N¹2. Enero - Junio. 2021 \\ Hecho el depósito de ley: pp201602FA4721 \\ ISSN-L: 2542-3029; ISSN: 2610-802X \\ Universidad Nacional Experimental Francisco de Miranda (UNEFM). Santa Ana de Coro. Venezuela \\ Rosa Angélica Zumba-Lucero; Juan Carlos Erazo-Álvarez; Gonzalo Iván Andrade-Mena \\ Cristián Andrés Erazo-Álvarez}

El logro del conocimiento estratégico del mercado del banano y de la aplicación de nuevas normas de calidad para crear nuevas ventajas competitivas y mantener las existentes, mediante la implementación de la gestión del conocimiento, exigirá el empleo de algún modelo de gestión del conocimiento. En este caso, el trabajo se apoyará en la propuesta de (Becerra-Fernández \& Sabberwal, 2010).

El proceso de Gestión del conocimiento propuesto por el autor antes mencionado, se sustenta en los siguientes pasos: 1) Sistemas de descubrimiento de conocimientos (Knowledge Discovery Systems); 2) Sistemas de captura del conocimiento (Knowledge Capture Systems); 3) Sistemas de distribución del conocimiento (Knowledge Sharing Systems); y 4) Sistemas aplicación de conocimientos (Knowledge Application Systems). El primer sistema es un conjunto de mecanismos para descubrir el conocimiento, empleando la socialización para crear nuevos conocimientos tácitos, lo que implica comunicación y relación permanente con los trabajadores, obteniéndose mucho de ello en la evaluación y seguimiento continuo de las labores, ya que se conforman maneras de enseñar conocimiento a los trabajadores bien de modo formal (talleres, conferencias) o con quienes coordinan el trabajo.

El segundo mecanismo consiste en sistemas que preservan y formalizan el conocimiento, es decir, elaborar y registrar la información obtenida para el uso y acceso frecuente. El tercer mecanismo consiste en sistemas que organizan y distribuyen el conocimiento adquirido, lo que lleva a organizar la memoria corporativa y se enlaza con la socialización porque se busca también cómo transmitirlo. El cuarto sistema tiene como finalidad el uso del conocimiento en casos concretos.

Los sistemas de aplicación aluden a tecnologías de inteligencia artificial, los sistemas basados en reglas, en razonamientos, entre otros, que son áreas muy especializadas manejadas fundamentalmente por los medios gerenciales y técnicos. En síntesis, se indagará fundamentalmente en la encuesta algunos indicadores sobre sistemas de descubrimiento (socialización, formación, aprendizaje mutuo) en vinculación con los 


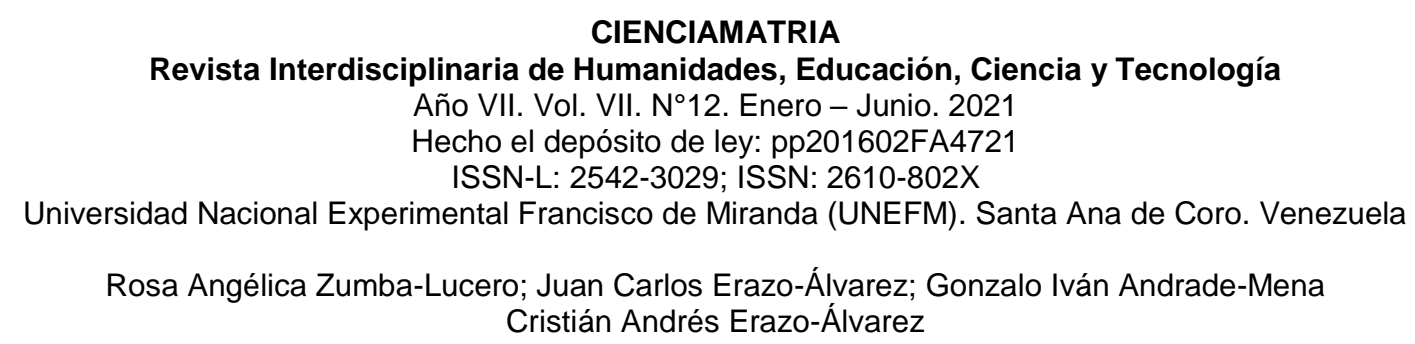

objetivos de la empresa y cómo esta busca integrar al trabajador en el proceso de gestión del conocimiento. Se entiende con ello que la gestión de conocimiento no puede estar separada de los objetivos estratégicos de la Hacienda La Candelaria. Además, en relación a la aplicación, esto no se medirá en sentido estricto, sino de modo indirecto, en relación a si ha habido cambios en las formas de hacer las actividades.

\section{MÉTODO}

La investigación se desarrolló desde el enfoque cuantitativo y una metodología de tipo descriptiva con diseño transversal no experimental, en una muestra poblacional conformada por 47 trabajadores de a Hacienda La Candelaria, ubicada en la Provincia de Chimborazo - Ecuador, aplicándoseles una encuesta online, apoyada en un cuestionario de 15 preguntas de diversas alternativas, siendo validada por el juicio de expertos y fiabilidad de Alfa de Cronbach con un resultado de 0,87 siendo considerado confiable para su aplicación, mientras que los datos recopilados fueron tabulados a partir de la estadística descriptiva, presentados en tablas de frecuencia y porcentajes.

\section{RESULTADOS}

Los resultados de la investigación se presentan en función de los cometidos planteados en el marco referencial. Se organizaron las preguntas de la encuesta a los trabajadores considerando la distinción de sistemas del proceso de gestión del conocimiento que hacen (Becerra-Fernández \& Sabberwal, 2010), de lo cual se escogió el sistema de descubrimiento de conocimiento que envuelve la socialización, la formación y el aprendizaje mutuo (ver Tabla 1).

Se incorporaron preguntas correspondientes con los objetivos de la empresa en tanto que se entiende que estos tienen que insertarse en la gestión del conocimiento para elevar la comprensión de los trabajadores sobre lo que la empresa aspira (ver Tabla 2). 
CIENCIAMATRIA

Revista Interdisciplinaria de Humanidades, Educación, Ciencia y Tecnología

Año VII. Vol. VII. N¹2. Enero - Junio. 2021

Hecho el depósito de ley: pp201602FA4721

ISSN-L: 2542-3029; ISSN: 2610-802X

Universidad Nacional Experimental Francisco de Miranda (UNEFM). Santa Ana de Coro. Venezuela

Rosa Angélica Zumba-Lucero; Juan Carlos Erazo-Álvarez; Gonzalo Iván Andrade-Mena Cristián Andrés Erazo-Álvarez

Se redactaron preguntas que pretenden captar una orientación indirecta sobre las modificaciones en el trabajo que la empresa realiza para mejorar las actividades productivas. A continuación, se exponen los resultados obtenidos de las entrevistas administradas a 47 trabajadores de la Hacienda La Candelaria.

\section{Indicadores del sistema de descubrimiento}

Los indicadores elaborados para respaldar el sistema de conocimiento en la Hacienda La Candelaria (ver Tabla 1), muestran que la empresa presenta debilidades manifestadas por los entrevistados que se ubicaron en porcentajes mayoritarios en las alternativas poca frecuencia en las preguntas alusivas al apoyo de la empresa a superar dificultades en el trabajo, a la receptividad de la empresa a propuestas del trabajador para mejorar su actividad, a solicitarle al trabajador si ha descubierto alguna mejora (el mayor de todos los porcentajes en la alternativa poca frecuencia) y la evaluación frecuente por parte de la empresa de las técnicas y procedimientos que utilizan los trabajadores.

Tabla 1.

Indicadores del sistema de descubrimiento de conocimiento.

\begin{tabular}{|c|c|c|c|}
\hline \multicolumn{4}{|c|}{$\begin{array}{l}\text { Indicadores del sistema de descubrimiento de conocimiento } \\
\text { (socialización, formación, aprendizaje mutuo) }\end{array}$} \\
\hline \multirow[t]{2}{*}{ Pregunta } & \multicolumn{3}{|c|}{$\begin{array}{c}\text { Alternativas de respuesta } \\
\text { (números absolutos y relativos) }\end{array}$} \\
\hline & $\begin{array}{l}\text { Mucha } \\
\text { frecuencia }\end{array}$ & $\begin{array}{l}\text { Poca } \\
\text { frecuencia }\end{array}$ & Nunca \\
\hline $\begin{array}{l}\text { ¿La empresa ha mostrado interés en apoyarlo a superar las } \\
\text { dificultades que se le han presentado en su trabajo? (Total: } \\
\text { 45) }\end{array}$ & $\begin{array}{c}19 \\
42 \%\end{array}$ & $\begin{array}{l}22 \\
49 \%\end{array}$ & $\begin{array}{c}4 \\
9 \%\end{array}$ \\
\hline $\begin{array}{l}\text { ¿La empresa ha sido receptiva a estudiar alguna propuesta } \\
\text { que usted haya hecho para mejorar alguna de las } \\
\text { actividades que realiza? (Total: } 44 \text { ) }\end{array}$ & $\begin{array}{c}17 \\
38,6 \%\end{array}$ & $\begin{array}{c}21 \\
47,7 \%\end{array}$ & $\begin{array}{c}6 \\
13,6 \%\end{array}$ \\
\hline $\begin{array}{l}\text { ¿La empresa le ha solicitado si ha podido descubrir alguna } \\
\text { mejora para la actividad que realiza? (Total: } 45 \text { ) }\end{array}$ & $\begin{array}{c}15 \\
33,3 \%\end{array}$ & $\begin{array}{c}27 \\
60 \%\end{array}$ & $\begin{array}{c}3 \\
6,6, \%\end{array}$ \\
\hline
\end{tabular}


CIENCIAMATRIA

Revista Interdisciplinaria de Humanidades, Educación, Ciencia y Tecnología

Año VII. Vol. VII. N¹2. Enero - Junio. 2021

Hecho el depósito de ley: pp201602FA4721

ISSN-L: 2542-3029; ISSN: 2610-802X

Universidad Nacional Experimental Francisco de Miranda (UNEFM). Santa Ana de Coro. Venezuela

Rosa Angélica Zumba-Lucero; Juan Carlos Erazo-Álvarez; Gonzalo Iván Andrade-Mena Cristián Andrés Erazo-Álvarez

\begin{tabular}{|c|c|c|c|}
\hline $\begin{array}{l}\text { ¿Puede decir la frecuencia con que la empresa le capacita } \\
\text { en conocimientos y técnicas para el trabajo? (Total: } 46 \text { ) }\end{array}$ & $\begin{array}{c}28 \\
61 \%\end{array}$ & $\begin{array}{c}13 \\
28 \%\end{array}$ & $\begin{array}{c}5 \\
11 \%\end{array}$ \\
\hline \multirow[t]{3}{*}{$\begin{array}{l}\text { ¿La empresa evalúa con frecuencia las técnicas y } \\
\text { procedimientos que utilizan los trabajadores en sus } \\
\text { labores? (Total: } 46 \text { ) }\end{array}$} & $\begin{array}{c}21 \\
45,65 \%\end{array}$ & $\begin{array}{c}22 \\
47,8 \%\end{array}$ & $\begin{array}{c}3 \\
6,5 \%\end{array}$ \\
\hline & \multicolumn{3}{|c|}{ Alternativas } \\
\hline & $\mathrm{Si}$ & No & \\
\hline $\begin{array}{l}\text { ¿Sabe usted que los trabajadores también son } \\
\text { importantes para que la empresa recopile los } \\
\text { conocimientos y técnicas para mejorar la producción del } \\
\text { banano? (Total: 45) }\end{array}$ & $\begin{array}{c}41 \\
91,1 \%\end{array}$ & $\begin{array}{c}4 \\
8,9 \%\end{array}$ & \\
\hline $\begin{array}{l}\text { ¿Necesita usted una mayor capacitación en el área de } \\
\text { trabajo que realiza? (Total: } 45 \text { ) }\end{array}$ & $\begin{array}{c}32 \\
71,1 \%\end{array}$ & $\begin{array}{c}13 \\
28,9 \% \\
\end{array}$ & \\
\hline $\begin{array}{l}\text { ¿Tiene la empresa un lugar acondicionado para hacer } \\
\text { actividades de capacitación con los trabajadores? (Total: } \\
\text { 46) }\end{array}$ & $\begin{array}{c}39 \\
84,7 \%\end{array}$ & $\begin{array}{c}7 \\
15,2 \%\end{array}$ & \\
\hline
\end{tabular}

Fuente: Elaboración propia.

En contraste, los trabajadores respondientes, en muy altos porcentajes (ver Tabla 1), afirman que conocen su propia importancia en la recopilación de la empresa de los conocimientos y técnicas para la producción del banano y dicen que la empresa tiene un lugar acondicionado para hacer actividades de capacitación con los trabajadores. Pero también manifiestan mayoritariamente que necesitan una mayor capacitación en el área de trabajo que realizan.

\section{Indicadores correspondientes con los objetivos de la empresa}

Con respecto a los indicadores referidos a los objetivos de la empresa (ver Tabla 2), los porcentajes reflejan fluidez en la comunicación de la Hacienda para hacer conocer lo que espera de su organización en los próximos tiempos. Lo cual tendría que estar relacionado con la información de la empresa hacia los trabajadores sobre una de sus opciones para mejorar la competitividad como es la producción de banano orgánico y la Norma Orgánica de Producción Europea. 


\section{CIENCIAMATRIA}

Revista Interdisciplinaria de Humanidades, Educación, Ciencia y Tecnología

Año VII. Vol. VII. N¹2. Enero - Junio. 2021

Hecho el depósito de ley: pp201602FA4721

ISSN-L: 2542-3029; ISSN: 2610-802X

Universidad Nacional Experimental Francisco de Miranda (UNEFM). Santa Ana de Coro. Venezuela

Rosa Angélica Zumba-Lucero; Juan Carlos Erazo-Álvarez; Gonzalo Iván Andrade-Mena Cristián Andrés Erazo-Álvarez

Tabla 2.

Indicadores del sistema de descubrimiento de conocimiento.

\begin{tabular}{|c|c|c|}
\hline \multicolumn{3}{|c|}{ Indicadores del sistema de descubrimiento de conocimiento } \\
\hline \multirow[t]{2}{*}{ Preguntas } & \multicolumn{2}{|c|}{ Alternativas } \\
\hline & $\mathrm{Si}$ & No \\
\hline $\begin{array}{l}\text { ¿Alguien de la empresa le ha explicado las razones por las que } \\
\text { la Hacienda necesita cambiar algunas formas de hacer las } \\
\text { cosas? (Total: } 45 \text { ) }\end{array}$ & $\begin{array}{c}29 \\
64,5 \%\end{array}$ & $\begin{array}{c}16 \\
35,5 \%\end{array}$ \\
\hline $\begin{array}{l}\text { ¿Le han explicado cuales son los objetivos que quiere alcanzar } \\
\text { la Hacienda la Candelaria en los próximos tiempos? (Total: } 44 \text { ) }\end{array}$ & $\begin{array}{c}32 \\
72,7 \%\end{array}$ & $\begin{array}{c}12 \\
27,3 \%\end{array}$ \\
\hline $\begin{array}{l}\text { ¿Alguien en la empresa le ha explicado en qué consiste la } \\
\text { Norma Orgánica de Producción Europea? (Total: } 43 \text { ) }\end{array}$ & $\begin{array}{c}16 \\
37 \%\end{array}$ & $\begin{array}{c}27 \\
62,8 \%\end{array}$ \\
\hline $\begin{array}{l}\text { ¿Sabe lo que quiere decir producción orgánica del banano? } \\
\text { (Total: } 46 \text { ) }\end{array}$ & $\begin{array}{c}35 \\
76 \%\end{array}$ & $\begin{array}{c}11 \\
24 \%\end{array}$ \\
\hline
\end{tabular}

Fuente: Elaboración propia.

Una mayoría de los trabajadores respondientes sabe lo que quiere decir producción orgánica del banano, pero una gran parte de los trabajadores encuestados la empresa no le ha hecho conocer en qué consiste la Norma Orgánica de Producción Europea. Se entiende que eso constituye una debilidad en la gestión del conocimiento en la Hacienda, porque uno de los pasos para que el conocimiento se inserte entre los trabajadores es que la empresa haga conocer cuáles son sus intereses. 
CIENCIAMATRIA

Revista Interdisciplinaria de Humanidades, Educación, Ciencia y Tecnología

Año VII. Vol. VII. N¹2. Enero - Junio. 2021

Hecho el depósito de ley: pp201602FA4721

ISSN-L: 2542-3029; ISSN: 2610-802X

Universidad Nacional Experimental Francisco de Miranda (UNEFM). Santa Ana de Coro. Venezuela

Rosa Angélica Zumba-Lucero; Juan Carlos Erazo-Álvarez; Gonzalo Iván Andrade-Mena Cristián Andrés Erazo-Álvarez

\section{Indicadores del sistema de aplicación de conocimientos}

\section{Tabla 3.}

Indicadores relacionados con el sistema aplicación de conocimientos.

\begin{tabular}{|c|c|c|c|}
\hline \multicolumn{4}{|c|}{ Indicadores relacionados con el sistema aplicación de conocimientos } \\
\hline \multirow[t]{2}{*}{ Preguntas } & \multicolumn{3}{|c|}{ Alternativas de respuesta } \\
\hline & $\mathrm{Si}$ & & No \\
\hline \multirow{3}{*}{$\begin{array}{l}\text { ¿Ha modificado alguna de sus actividades en } \\
\text { el trabajo por recomendaciones de cambio de } \\
\text { su jefe inmediato en los últimos } 3 \text { años? (Total: } \\
\text { 45) }\end{array}$} & $\begin{array}{c}30 \\
66,6 \%\end{array}$ & & $\begin{array}{c}15 \\
33,3 \%\end{array}$ \\
\hline & \multicolumn{3}{|c|}{ Alternativas de respuesta } \\
\hline & Más de una vez & Una vez & Ninguna \\
\hline \multirow{2}{*}{$\begin{array}{l}\text { ¿Ha cambiado la organización del trabajo en el } \\
\text { tiempo que lleva laborando en la Hacienda? } \\
\text { (Total: } 45 \text { ) }\end{array}$} & $\begin{array}{c}26 \\
57,8 \%\end{array}$ & $\begin{array}{c}14 \\
31,1 \%\end{array}$ & $\begin{array}{c}5 \\
11 \%\end{array}$ \\
\hline & $\begin{array}{l}\text { Ha aprendido } \\
\text { continuamente }\end{array}$ & $\begin{array}{c}\text { Poco ha } \\
\text { aprendido }\end{array}$ & $\begin{array}{c}\text { Hace igual las } \\
\text { cosas }\end{array}$ \\
\hline $\begin{array}{l}\text { ¿En su trabajo en la Hacienda ha estado } \\
\text { aprendiendo continuamente o hace las cosas } \\
\text { igual a lo que se le indicó desde el principio de } \\
\text { su actividad? (Total: 45) }\end{array}$ & $\begin{array}{c}25 \\
55,6 \%\end{array}$ & $\begin{array}{c}16 \\
35,5 \%\end{array}$ & $\begin{array}{c}4 \\
8,8 \%\end{array}$ \\
\hline
\end{tabular}

Fuente: Elaboración propia.

Sobre los indicadores de aplicación de conocimientos (ver Tabla 3), los trabajadores informan que ha habido cambios tanto en las actividades que realizan como en la organización del trabajo en porcentajes superiores al $50 \%$, lo cual denota interés por parte de la empresa en el mejoramiento de las labores, aun cuando los porcentajes no son elevados y todavía ello no es generalizado. Además, el aprendizaje continuo todavía no envuelve a un amplio porcentaje de los trabajadores encuestados. 


\section{CIENCIAMATRIA}

Revista Interdisciplinaria de Humanidades, Educación, Ciencia y Tecnología

Año VII. Vol. VII. N¹2. Enero - Junio. 2021

Hecho el depósito de ley: pp201602FA4721

ISSN-L: 2542-3029; ISSN: 2610-802X

Universidad Nacional Experimental Francisco de Miranda (UNEFM). Santa Ana de Coro. Venezuela

Rosa Angélica Zumba-Lucero; Juan Carlos Erazo-Álvarez; Gonzalo Iván Andrade-Mena

Cristián Andrés Erazo-Álvarez

\section{PROPUESTA}

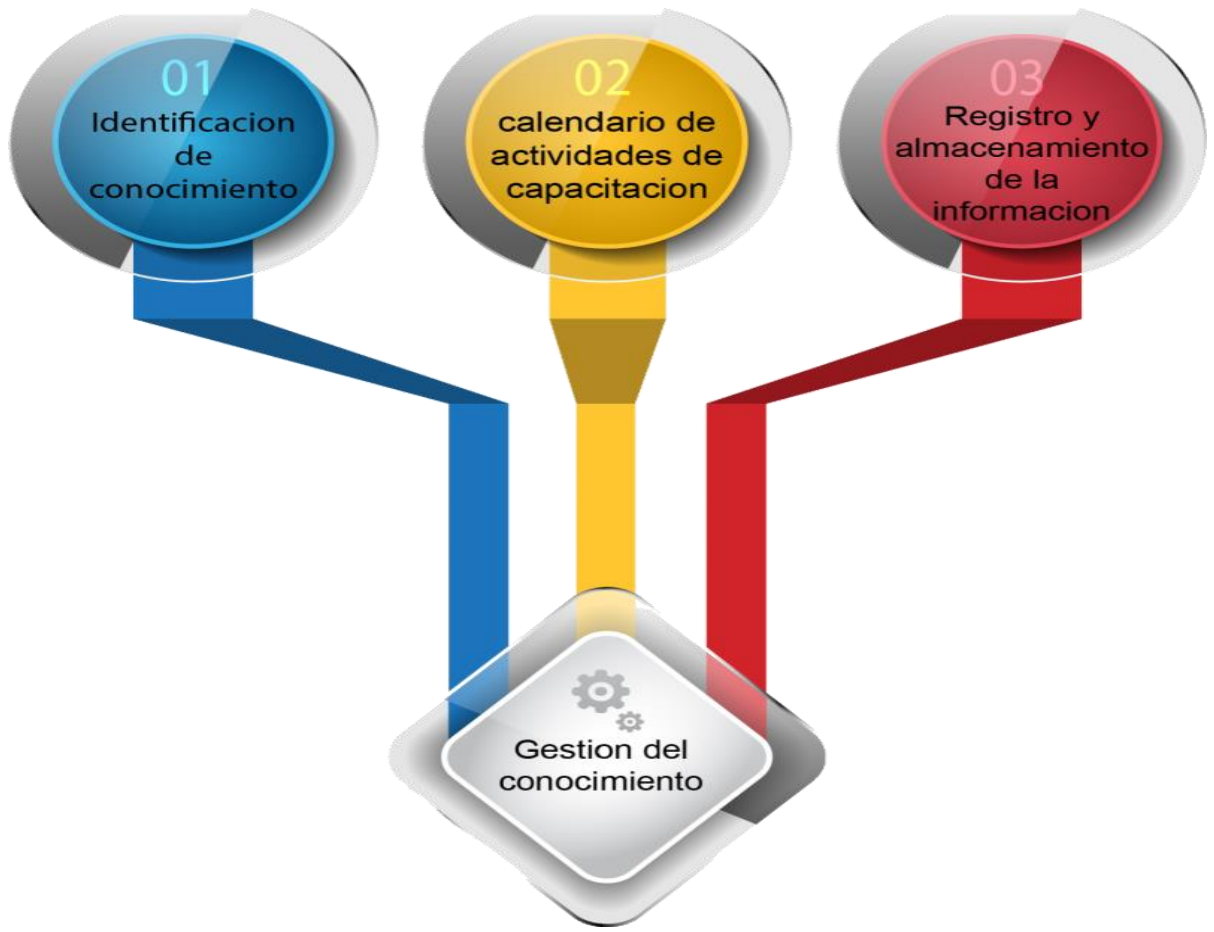

Figura 1. Estructura de la propuesta de investigación.

La propuesta que se elabora para la Hacienda La Candelaria sobre gestión del conocimiento tiene como objetivo optimizar el aprendizaje, disponibilidad y acceso a la información y conocimientos que mejoren las habilidades de los trabajadores en el manejo orgánico del cultivo del banano en los distintos procesos de producción, distribución y comercialización. La propuesta alude a tres aspectos básicos: identificación del conocimiento, registro y almacenamiento de la información, calendario de actividades de capacitación e indicadores de su medición, que se describen a continuación. 
CIENCIAMATRIA

Revista Interdisciplinaria de Humanidades, Educación, Ciencia y Tecnología

Año VII. Vol. VII. N¹2. Enero - Junio. 2021

Hecho el depósito de ley: pp201602FA4721

ISSN-L: 2542-3029; ISSN: 2610-802X

Universidad Nacional Experimental Francisco de Miranda (UNEFM). Santa Ana de Coro. Venezuela

Rosa Angélica Zumba-Lucero; Juan Carlos Erazo-Álvarez; Gonzalo Iván Andrade-Mena

Cristián Andrés Erazo-Álvarez

\section{Identificación del conocimiento de los trabajadores}

La empresa necesita que los trabajadores tengan y obtengan el conocimiento necesario para el ejercicio laboral y debe buscarlo dentro o fuera de la empresa cuando experimenta esas carencias (León, et al., 2016). Una de las primeras acciones para acometer el proceso de gestión del conocimiento es identificar las necesidades de capacitación de su fuerza laboral.

Los resultados de la encuesta administrada revelaron que una parte de los trabajadores $(71,1 \%)$ tiene necesidad de una mayor capacitación y el $35,5 \%$ dijo no haber tenido un aprendizaje continuo. Un medio para saber cuáles son las necesidades de capacitación es contar con un formulario diagnóstico que facilite información útil para orientar la gestión de conocimiento, el cual se propone a continuación.

\section{Tabla 4.}

Necesidades de formación.

\section{Hacienda La Candelaria}

Necesidades de formación (Datos básicos)

Nombres

Apellidos

Cargo

Tareas asociadas al cargo

Aspectos técnicos del cargo que ocupa

Cursos realizados

Temas de interés para capacitación

Fecha 
CIENCIAMATRIA

Revista Interdisciplinaria de Humanidades, Educación, Ciencia y Tecnología

Año VII. Vol. VII. N¹2. Enero - Junio. 2021

Hecho el depósito de ley: pp201602FA4721

ISSN-L: 2542-3029; ISSN: 2610-802X

Universidad Nacional Experimental Francisco de Miranda (UNEFM). Santa Ana de Coro. Venezuela

Rosa Angélica Zumba-Lucero; Juan Carlos Erazo-Álvarez; Gonzalo Iván Andrade-Mena

Cristián Andrés Erazo-Álvarez

\section{Registro y almacenamiento de la información}

El conocimiento en la empresa puede ser transferido en las relaciones interpersonales, pero para la empresa es crucial la distribución de conocimiento de acuerdo a los requerimientos que desea alcanzar. Es por ello que la organización requiere tener un registro de información con algún tipo de software de preferencia para garantizar que el mismo sea organizado y de acceso expedito (León, et al., 2016). La organización básica de la información sobre el conocimiento generado por la propia empresa y la obtenida de medios externos, tiene que ser discriminada según las áreas de conocimiento de interés. La organización básica del registro se presenta en la tabla 5.

\section{Tabla 5.}

Registro de Información.

\begin{tabular}{|c|c|c|c|}
\hline \multicolumn{4}{|c|}{ Hacienda La Candelaria } \\
\hline & & Interna & Externa \\
\hline \multicolumn{4}{|c|}{$\begin{array}{l}\text { 1. Sistema de plantación } \\
\text { 1.1. Selección del terreno. } \\
\text { 1.2. Preparación del terreno. } \\
\text { 1.3. Distribución de canales y drenajes. } \\
\text { 1.4. Siembra. } \\
\text { 1.5. Control de malas hierbas. } \\
\text { 1.6. Fertilización. } \\
\text { 1.7. Riego. } \\
\text { 1.8. Desijado. } \\
\text { 1.9. Deshojado } \\
\text { 1.10. Apuntalado. } \\
\text { 1.11. Enfundado. } \\
\text { 1.12. Desmane. }\end{array}$} \\
\hline \multicolumn{4}{|c|}{$\begin{array}{l}\text { 2. Producción orgánica } \\
\text { 2.1. Normativa orgánica nacional } \\
\text { 2.2. Normativas orgánicas internacionales }\end{array}$} \\
\hline & $\begin{array}{l}\text { Enfermedades } \\
\text { 3.1. Plagas }\end{array}$ & & \\
\hline & $\begin{array}{l}\text { Características de los suelos } \\
\text { 4.1. Exigencias edafoclimáticas } \\
\text { 4.2. Calidad del suelo }\end{array}$ & & \\
\hline
\end{tabular}


CIENCIAMATRIA

Revista Interdisciplinaria de Humanidades, Educación, Ciencia y Tecnología

Año VII. Vol. VII. N¹2. Enero - Junio. 2021

Hecho el depósito de ley: pp201602FA4721

ISSN-L: 2542-3029; ISSN: 2610-802X

Universidad Nacional Experimental Francisco de Miranda (UNEFM). Santa Ana de Coro. Venezuela

Rosa Angélica Zumba-Lucero; Juan Carlos Erazo-Álvarez; Gonzalo Iván Andrade-Mena

Cristián Andrés Erazo-Álvarez

\begin{tabular}{|c|c|}
\hline & $\begin{array}{l}\text { 4.3. Evaluación de calidad del suelo } \\
\text { 4.4. Elementos físico-químicos } \\
\text { 4.5. Elementos biológicos }\end{array}$ \\
\hline 5. & $\begin{array}{l}\text { Nutrición del cultivo } \\
\text { 5.1. Fertilizantes convencionales } \\
\text { 5.2. Fertilizantes orgánicos }\end{array}$ \\
\hline & Cosecha \\
\hline 7. & $\begin{array}{l}\text { Corte } \\
\text { 7.1. Empacado }\end{array}$ \\
\hline & $\begin{array}{l}\text { Embolsado } \\
\text { 8.1. Encintado }\end{array}$ \\
\hline & Transportación \\
\hline
\end{tabular}

La ficha de registro organiza la información existente relacionada con la producción del banano, de acuerdo a la bibliografía especializada (InfoAgro, 2020). Su importancia está en que constituye una manera de ayudar a quienes expresan que necesitan una mayor formación para el trabajo o que presentan ciertas dificultades en el mismo, según se obtuvo en la encuesta.

Así como también, la información registrada sirve para las actividades de formación que ejercen quienes se encargan de la gestión del conocimiento (aprendizaje- socialización), por ello, el tener la información desagregada en interna y externa, es una forma de distinguir en el registro los alcances propios para la memoria histórica del proceso de descubrimiento realizado. Con el tiempo, la empresa va generando un registro propio de sus alcances específicos de conocimiento en correspondencia con sus metas.

\section{Calendario de actividades de capacitación}

Se presenta en la Tabla 6 un calendario de actividades de capacitación bimensual según áreas de conocimiento propias de la empresa bananera para formalizar la ejecución de las mismas en el tiempo y observar la atención al desarrollo de capacidades en las distintas actividades de la Hacienda. 
CIENCIAMATRIA

Revista Interdisciplinaria de Humanidades, Educación, Ciencia y Tecnología

Año VII. Vol. VII. N¹2. Enero - Junio. 2021

Hecho el depósito de ley: pp201602FA4721

ISSN-L: 2542-3029; ISSN: 2610-802X

Universidad Nacional Experimental Francisco de Miranda (UNEFM). Santa Ana de Coro. Venezuela

Rosa Angélica Zumba-Lucero; Juan Carlos Erazo-Álvarez; Gonzalo Iván Andrade-Mena

Cristián Andrés Erazo-Álvarez

\title{
Tabla 6.
}

Registro de Información.

\section{Hacienda la Candelaria}

\author{
Área Asociada \\ Sistema de plantación \\ Producción orgánica \\ Enfermedades y plagas \\ Características de suelos \\ Nutrición del cultivo \\ Cosecha \\ Corte \\ Embolsado \\ Transportación
}

Curso, charla, taller, brainstorm u otras

Fecha

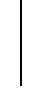

\section{Indicadores de medición de la capacitación}

Se proponen indicadores sencillos y manejables para la medición de la capacitación (Wormhole, 2017), los cuales son: número de participantes en las actividades realizadas según los calendarios bimensuales, para saber su incremento o disminución y promedios de asistencia, medir el tiempo de la capacitación de acuerdo al número de horas de la actividades desarrolladas, promedio de calificaciones de los participantes según el sistema de evaluación escogido (cualitativo o cuantitativo) y medir el nivel de satisfacción de los participantes con dos preguntas básicas, sobre si los contenidos fueron entendidos y si le resuelven dudas o dificultades (Tabla 7). Cada seis meses se evaluarían esas mediciones y se efectúan las modificaciones a que haya lugar. 
CIENCIAMATRIA

Revista Interdisciplinaria de Humanidades, Educación, Ciencia y Tecnología

Año VII. Vol. VII. N¹2. Enero - Junio. 2021

Hecho el depósito de ley: pp201602FA4721

ISSN-L: 2542-3029; ISSN: 2610-802X

Universidad Nacional Experimental Francisco de Miranda (UNEFM). Santa Ana de Coro. Venezuela

Rosa Angélica Zumba-Lucero; Juan Carlos Erazo-Álvarez; Gonzalo Iván Andrade-Mena

Cristián Andrés Erazo-Álvarez

\section{Tabla 7.}

Indicadores de medición semestral de la capacitación.

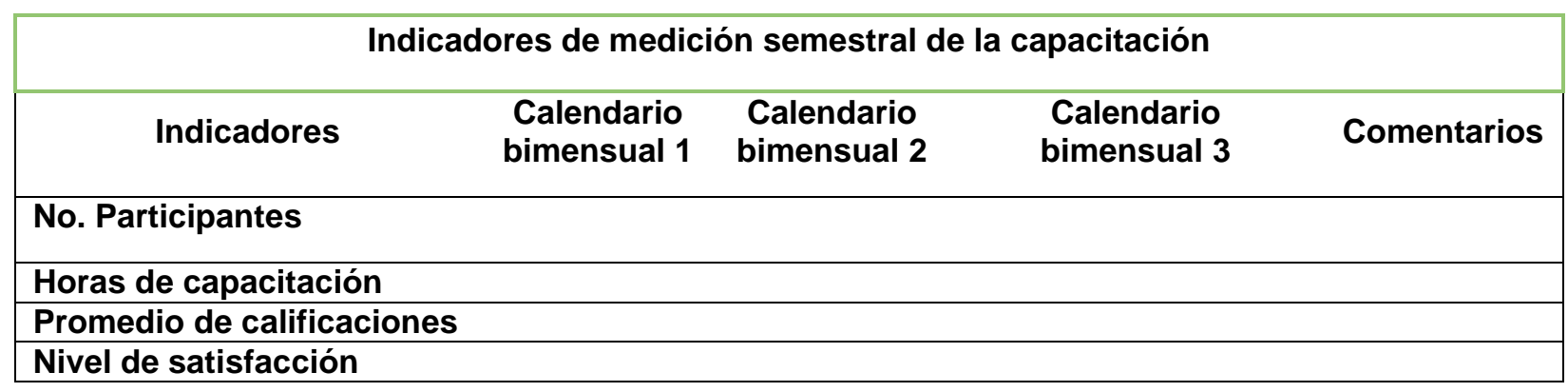

\section{CONCLUSIONES}

Se concluye que la Hacienda La Candelaria mantiene un relativa atención a la formación de sus trabajadores pero no cuenta con procesos sólidos de gestión del conocimiento en lo atinente al sistema de descubrimiento, los trabajadores manifiestan la necesidad de una mejor formación y los esfuerzos de la empresa por resolverles dificultades en el trabajo y realizar actividades permanentes de evaluación y monitoreo de lo aprendido y de las oportunidades de aprender asuntos nuevos en el propio trabajo son insuficientes. Hay fallas de sincronía entre los coordinadores y trabajadores de la empresa, si se entiende que la Hacienda es una organización sistémica, tal como fue tratado en el referente teórico el funcionamiento de las organizaciones, todos los trabajadores deben estar suficientemente informados sobre los objetivos de la Hacienda, en especial con respecto a la Norma Europea antes dicha, es un paso informativo importante si la empresa busca ampliar su competitividad accediendo a esa certificación, que requiere cambios significativos en toda la cadena de producción y comercialización con el mercado europeo.

Además, en una empresa que busca mejores estándares de calidad, internacionales particularmente, necesariamente tiene que implementar el aprendizaje continuo y el monitoreo del mismo como forma de especializar su recurso humano. Incluso, aunque no todos los trabajadores tengan que hacer cambios en la actividad que realizan, todos por 


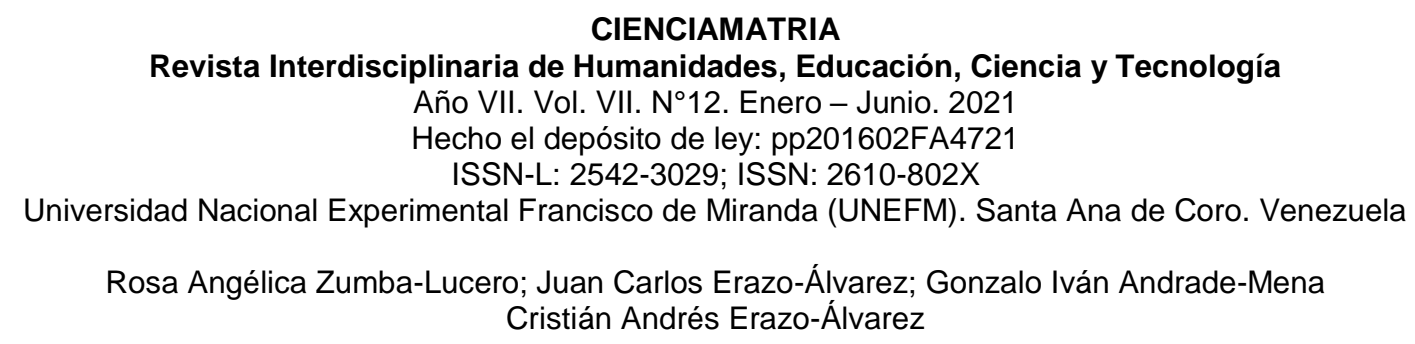

igual deben estar informados de las mejoras que se realicen, ya ello genera empatías que mejoran la motivación y los trabajadores pueden sentirse considerados como miembros del conjunto humano de la Hacienda, lo cual puede ayudar en muchos otros aspectos a la empresa.

La empresa tiene fallas en el seguimiento y ayuda a las dificultades que tienen sus trabajadores en la ejecución de su trabajo, lo cual es contraproducente porque tales insuficiencias pueden estarse solventando de modos contraproducentes a la calidad que busca la empresa, por ejemplo, mediante formas de resolución que se aportan los trabajadores entre sí pero que no necesariamente se insertan dentro de lo que la empresa requiere dados los objetivos que busca.

Todo lo anterior indica que la Hacienda La Candelaria requiere de un plan de gestión del conocimiento que articule y adapte los diferentes aspectos que (Becerra-Fernández \& Sabberwal, 2010), entre otros autores, han desarrollado para las organizaciones, para mejorar su actividad productiva y competitividad.

\section{REFERENCIAS CONSULTADAS}

Ahn, J. H., \& Chang, S. G. (2004). Assessing the contribution of knowledge to business performance: the KP3 methodology [Evaluación de la contribución de los conocimientos al rendimiento empresarial: la metodología del KP3]. Decision Support Systems 36(4), 403-416.

Avila Ramírez, P., Mendoza, A., Meza, J., \& Zambrano, M. (2018). La gerencia estratégica, análisis del enfoque en las empresas. https://n9.cl/quc1b

Beazley, H., Boenisch, J., \& Harden, D. (2002). Continuity Management: Preserving Corporate Knowledge y Productivity when Employees leave first [Gestión de la continuidad: Preservar el conocimiento y la productividad de la empresa cuando los empleados se van primero]. New York: John Wiley edn. 
Revista Interdisciplinaria de Humanidades, Educación, Ciencia y Tecnología

Año VII. Vol. VII. N¹2. Enero - Junio. 2021

Hecho el depósito de ley: pp201602FA4721

ISSN-L: 2542-3029; ISSN: 2610-802X

Universidad Nacional Experimental Francisco de Miranda (UNEFM). Santa Ana de Coro. Venezuela

Rosa Angélica Zumba-Lucero; Juan Carlos Erazo-Álvarez; Gonzalo Iván Andrade-Mena Cristián Andrés Erazo-Álvarez

Becerra-Fernández, I., \& Sabberwal, R. (2010). Knowledge Management. Systems and processes [Gestión del conocimiento. Sistemas y proceso]. New York: Sharpe, Inc.

Benavides, C., \& Quintana, C. (2003). Gestión del conocimiento y calidad total. Madrid, España: Ediciones Díaz de Santos.

Borgucci, E. (2013). Introducción al análisis gerencial de los estados financieros [Introduction to Management Analysis of Financial Statements]. Maracaibo: Vicerrectorado Académico.

Chang, L. K., Lee, S., \& Kang, I. w. (2005). KMPI: measuring knowledge management performance. Information \& Management 42(3), 469-482.

Conner, K., \& Prahalad, C. (1996). A resource-based theory of the firm: knowledge versus opportunism [Una teoría de la empresa basada en los recursos: conocimiento versus oportunismo]. Organization Science 7(5), 477-501.

Davenport, T., De Long, D., \& Beers, M. (1998). Successful knowledge management projects [Proyectos exitosos de gestión de los conocimientos]. Sloan Management Review 39(2), 43-57.

De Long, D., \& Fahey, L. (2000). Diagnosing cultural barriers to knowledge management [Diagnóstico de las barreras culturales a la gestión de los conocimientos]. Academy of Management Executive 14(4), 113-127.

Del Moral, A., Pazos, J., Rodríguez, E., Rodríguez, A., \& Suárez, S. (2007). Gestión del conocimiento [Knowledge Management]. España: Thompson Editores.

Demarest, M. (1997). Understanding knowledge management. Long Range Planning 30(3), 374-384.

Dyer, J., \& Nobeoka, K. (2000). Creating and managing a high performance knowledgesharing network: the Toyota case [Creación y gestión de una red de intercambio de conocimientos de alto rendimiento: el caso Toyota]. Strategic Management Journal 21(3), 345-367.

Eisenberg, H. (1997). Reengineering and dumbsizing: mismanagement of the knowledge resource [Reingeniería y dumbsizing: mala gestión del recurso del conocimiento]. Quality Progress 30(5), 57-64. 


\section{CIENCIAMATRIA}

Revista Interdisciplinaria de Humanidades, Educación, Ciencia y Tecnología

Año VII. Vol. VII. N¹2. Enero - Junio. 2021

Hecho el depósito de ley: pp201602FA4721

ISSN-L: 2542-3029; ISSN: 2610-802X

Universidad Nacional Experimental Francisco de Miranda (UNEFM). Santa Ana de Coro. Venezuela

Rosa Angélica Zumba-Lucero; Juan Carlos Erazo-Álvarez; Gonzalo Iván Andrade-Mena Cristián Andrés Erazo-Álvarez

Fayyad, U., Piatetsky-Shapiro, G., \& Smyth, P. (1996). From data mining to knowledge discovery. In Advances in Knowledge Discovery and Data Mining. Fayyad U. Piatetsky-Shapiro, G. Smyth, P. y Uthurusamy, R. Eds, 1-36.

Food and Agriculture Organization of the United Nations, FAO . (2019). Banana Market Review: Preliminary Results 2019. https://n9.cl/xateh

Foray, D. (2004). Economics of Knowledge [Economía del Conocimiento]. Cambridge, MA.: MIT Press.

FreshPlaza. (2020). Resumen del Mercado global de la banana. Recuperado de https://n9.cl/190l3

Girard, J.P., \& Girard, J.L. (2015). Defining knowledge management: Toward an applied compendium, Online Journal of Applied Knowledge Management. 3(1), 1-20

Glazer, R. (1998). Measuring the knower: towards a theory of knowledge equity. California Management Review 40(3), 175-194.

GLOBALG.A.P. (2020). 5 pasos para obtener la certificación. https://n9.cl/grc7j

Graham, A., \& Pizzo, V. (1996). A question of balance: case studies in strategic knowledge management [Una cuestión de equilibrio: estudios de casos en la gestión estratégica del conocimiento]. European Management Journal 14(4), 338346.

InfoAgro. (2020). El cultivo del plátano (1 ${ }^{a}$ parte). Recuperado de https://n9.cl/alo3

Inkpen, A., \& Tsang, E. (2005). Social capital, networks, and knowledge transfer [Capital social, redes y transferencia de conocimientos]. Academy of Management Review 30(1), 146.

Jordan, J., \& Jones, P. (1997). Assessing your company's knowledge management style. Long Range Planning 30(3), 392-398.

Kafentzis, K., Mentzas, G., Apostolou, D., \& Georgolios, P. (2004). Knowledge marketplaces: strategic issues and business models [Los mercados del conocimiento: cuestiones estratégicas y modelos de negocio]. Journal of Knowledge Management 8(1), 130. 
Revista Interdisciplinaria de Humanidades, Educación, Ciencia y Tecnología

Año VII. Vol. VII. N¹2. Enero - Junio. 2021

Hecho el depósito de ley: pp201602FA4721

ISSN-L: 2542-3029; ISSN: 2610-802X

Universidad Nacional Experimental Francisco de Miranda (UNEFM). Santa Ana de Coro. Venezuela

Rosa Angélica Zumba-Lucero; Juan Carlos Erazo-Álvarez; Gonzalo Iván Andrade-Mena Cristián Andrés Erazo-Álvarez

King, A., \& Zeithaml, C. (2003). Measuring organizational knowledge: a conceptual and methodological framework. Strategic Management Journal 24(8), 763.

Kogut, B., \& Zander, U. (1997). Knowledge of the Firm, Combinative Capabilities, and the Replication of Technology. Organization Science, 3(3). https://doi.org/10.1287/orsc.3.3.383

León, M., Ponjuan, G., \& Rodrígues, M. (2016). Procesos estratégicos de la gestión del conocimiento. https://cutt.ly/YkQCpqK

Martínez G., Delgado E., Pargas R., Manzanilla E., Ramírez H. 2007. Consideraciones generales sobre la producción y el comercio mundial de banano. I: producción, exportación e importación. Revista Digital CENIAP Hoy No. 13.

Mintzberg, H. (1987). Crafting Strategy [Elaboración de la estrategia]. Harvard Business Review 65, 66-75. https://n9.cl/srr7h

Nonaka, I., \& Takeuchi, H. (1995). The Knowledge-Creating Company: How Japanese Companies Create the Dynamics of Innovation [La Compañía Creadora de Conocimientos: Cómo las empresas japonesas crean la dinámica de la innovación]. New York: Oxford University Press.

Nonaka, I., \& Toyama, R. (2003). Knowledge-creating theory revisited. Knowledge Management Research and Practice 1(1), 2-10. https://doi.org/10.1057/palgrave.kmrp.8500001

Organización de las Naciones Unidas para la Alimentación y la Agricultura. (2020). Certificación Orgánica de Bananos. https://n9.cl/lgjd

Pardo, C., \& Novillo, E. (2016). Proceso de control de calidad para el banano de exportación en finca bananera. https://n9.cl/yua5f

Pérez-Montoro, M. (2016). Gestión del conocimiento: orígenes y evolución. Profesional De La Información, 25(4), 526-534. https://doi.org/10.3145/epi.2016.jul.02

Reyes, P. E., Narváez, C. I., Erazo, J. C., \& Giler, L. V. (2020). Configuración del impuesto a la patente municipal con base al ingreso de las actividades económicas. Caso: GAD Municipal de Pucará - Ecuador. Revista Espacios, 41(21), 197-211. Recuperado de: https://n9.cl/8fvf 
CIENCIAMATRIA

Revista Interdisciplinaria de Humanidades, Educación, Ciencia y Tecnología

Año VII. Vol. VII. N¹2. Enero - Junio. 2021

Hecho el depósito de ley: pp201602FA4721

ISSN-L: 2542-3029; ISSN: 2610-802X

Universidad Nacional Experimental Francisco de Miranda (UNEFM). Santa Ana de Coro. Venezuela

Rosa Angélica Zumba-Lucero; Juan Carlos Erazo-Álvarez; Gonzalo Iván Andrade-Mena

Cristián Andrés Erazo-Álvarez

Rosero, J. L. (2001). Un análisis sobre la competitividad del banano ecuatoriano. Apuntes de Economía № 17, 2-23. https://n9.cl/5o6wy

Stanclife, D. (1917). Essays in the earlierhitory of American corporations [Ensayos en la historia anterior de las corporaciones americanas]. Recuperado de https://n9.cl/bau4

Starbuck, W. (1997). Learning by knowledge-intensive firms. In Knowledge in Organizations [Aprendizaje por parte de las empresas de conocimiento intensivo. En el conocimiento en las organizaciones]. Prusak L, Ed, 147-175.

Teece, D. J. (2000). Strategies for managing knowledge assets: the role of firm structure and industrial context [Estrategias para la gestión de los activos del conocimiento: el papel de la estructura de la empresa y el contexto industrial]. Long Range Planning 33(1), 35-54.

Tordoir, P. (1995). The Professional Knowledge Economy [La economía del conocimiento profesional]. Dordrecht: Kluwer Academic Publishers.

UNCTAD. (2014). Estudio base para la revisión de la política de exportación de productos verdes del Ecuador. Conferencia de las Naciones Unidas sobre Comercio y Desarrollo. Ecuador: Publicaciones de las Naciones Unidas. https://n9.cl/acan1

Vásquez-Ramírez, L, \& Castaño-Zapata, J. (2017). Manejo integrado de la marchitez vascular del tomate: una revisión. Revista U.D.C.A Actualidad \& Divulgación Científica, 20(2), 363-374.

Wiig, K. (1993). Knowledge Management Foundations - Thinking about Thinking - How People and Organizations Create, Represent and Use Knowledge [Fundamentos de la gestión del conocimiento - Pensar sobre el pensamiento - Cómo las personas y las organizaciones crean, repres]. Arlington Texas: Schema Press.

Wormhole. (2017). 5 Métricas e indicadores para la capacitación y desarrollo del talento. HR Analytics. Parte IV. https://cutt.ly/NkQCLG9

Zamora, E. (2003). Gestión de conocimiento organizacional. Marco de referencia teórico para la investigación sobre los procesos de conocimiento en las organizaciones de la sociedad civil de Centroamérica [Organizational knowledge management. Theoretical reference framework]. Costa Rica: Fundación Acceso. 


\section{CIENCIAMATRIA}

Revista Interdisciplinaria de Humanidades, Educación, Ciencia y Tecnología

Año VII. Vol. VII. Nº12. Enero - Junio. 2021

Hecho el depósito de ley: pp201602FA4721

ISSN-L: 2542-3029; ISSN: 2610-802X

Universidad Nacional Experimental Francisco de Miranda (UNEFM). Santa Ana de Coro. Venezuela

Rosa Angélica Zumba-Lucero; Juan Carlos Erazo-Álvarez; Gonzalo Iván Andrade-Mena Cristián Andrés Erazo-Álvarez

(C2021 por los autores. Este artículo es de acceso abierto y distribuido según los términos y condiciones de la licencia Creative Commons Atribución-NoComercial-Compartirlgual 4.0 Internacional (CC BY-NC-SA 4.0) (https://creativecommons.org/licenses/by-nc-sa/4.0/ 